\title{
Statistical process control Application in waiting time at a hospital
}

\author{
Rosimeire Freires Pereira Oliveira ${ }^{\mathbf{1}}$; Sidney Dos Santos Oliveira ${ }^{2}$. \\ 1,2 Programa de Pós-graduação em Engenharia de Processos (PPGEP) da Universidade Federal do Pará (UFPA). Campus Guamá \\ Rua Augusto Correa No 01. Belém, PA. CEP: 66075-110. Caixa Postal 479. Tel: +55 9235846145 / +55 9232482646. \\ 1,2Manaus-Amazonas-Brasil.(rosimeirefpol@yahoo.com.br, sidneyoliveira54@yahoo.com.br )
}

\begin{abstract}
The Statistical Process Control (SPC) is a tool that aims to develop and apply statistical methods as part of a strategy to prevent and diagnose problems, to bring a parameter to apply the quality system improvements. In a scenario that quality is critical to customer satisfaction (patient), this includes the waiting time in service, making it necessary to search for continuous improvement. Since the public sector has sought to adhere to the new management concepts, to improve the quality of care, which requires the continuous improvement of processes, resulting in reduced variability in waiting time. The use of SPC has proven to be an effective alternative, its use can be used in all segments of both public and private companies. This research aims to present the implementation of the SPC for users to call time in a Hospital of Public Emergency and Emergency Unit waiting in Apuí municipality in the state of Amazonas. The methodology used was literature, questionnaire, interview, direct observation and data collection through technical visits, developed in the form of case study, and the analysis of medical records. In this study, the results indicated that users have had a longer wait time than allowed by the guidelines of the Emergency Unit, which is a maximum of 120 minutes to cases with no risk of death, so that is not meeting the efficient way to users, thereby bringing many losses to society of this city. After the survey was proposed that the initial care 6am in the morning and hiring doctors to meet demand. Therefore, the SPC was efficient to diagnose problems, bringing the root cause, for better implementation of the improvements.
\end{abstract}

Keywords: Statistical Process Control. Control chart. Standard deviation. Continuous improvement.

\section{Aplicação do controle estatístico de processo no tempo de espera em uma unidade hospitalar}

\begin{abstract}
RESUMO
O Controle estatístico do processo (CEP) é uma ferramenta que tem por finalidade desenvolver e aplicar métodos estatísticos como parte de estratégia para prevenção e diagnóstico de problemas, por trazer um parâmetro, para aplicar as melhorias da qualidade no sistema. Num cenário que a qualidade é primordial para a satisfação do cliente (paciente), isso inclui o tempo de espera no atendimento, fazendo-se necessário uma busca da melhoria continua. Visto que, o setor público tem buscado aderir aos novos conceitos de administração, procurando melhorar a qualidade no atendimento, isso exige a melhoria contínua dos processos, implicando-se na redução de variabilidade no tempo de espera. A utilização do CEP tem se mostrado uma alternativa eficaz, podendo ser aplicada em todos os seguimentos tanto de empresas públicas, quanto privadas. Esta pesquisa tem como objetivo apresentar a aplicação do CEP no tempo de espera do atendimento dos usuários em uma Unidade Pública Hospitalar de Urgência e Emergência no município de Apuí no Estado do Amazonas. A metodologia utilizada foi o levantamento bibliográfico, aplicação de questionário, entrevista, observação direta e coleta de dados através de visitas técnicas, desenvolvido sobre forma de estudo de caso, além da análise dos prontuários. Neste estudo, os resultados apontaram que os usuários têm levado um tempo de espera maior do que permitido pelas diretrizes de uma unidade de Urgência que é de no máximo 120 minutos para casos sem risco de morte, de forma que não está atendendo os usuários de maneira eficiente, trazendo assim muitos prejuízos para a sociedade deste município. Após os levantamentos foi proposto que o atendimento inicie às $6 \mathrm{hs}$ da manhã e a contratação de médicos para atender a demanda. Portanto, o CEP se mostrou eficiente para diagnosticar problemas, trazendo a causa- raiz, para uma melhor aplicação das melhorias.
\end{abstract}

Palavra- Chaves: Gráfico de controle. Desvio Padrão. Melhoria contínua.

\section{INTRODUÇÃO}

A superlotação das Unidades hospitalar, a falta de médicos tem causado um grande aumento no tempo de espera dos usuários no atendimento, é um problema de direito humano, não se restringe não só a saúde.

Deve-se ter uma atenção às unidades hospitalar de urgências, de forma que atendam as necessidades dos usuários, 
Rosimeire F. P. Oliveira, Sidney dos S. Oliveira / ITEGAM-JETIA Vol.02, No 07, pp.69-83. Setembro, 2016.

para que a mesma possa prestar um serviço com maior eficiência, garantindo assim a atenção nas linhas prioritárias, em articulação com os demais pontos de atenção.

Com direitos iguais para todos e integralidade na recepção baseada nas suas necessidades de saúde, priorizando mediante acolhimento com classificação de risco, segundo grau de sofrimento, urgência e gravidade do caso, com atendimento ininterrupto nas 24 (vinte e quatro) horas do dia e em todos os dias da semana. [1].

A aplicação do CEP nos prontuários de atendimento das Unidades Hospitalares visa trazer um parâmetro de seu processo, que está o serviço prestado aos usuários do serviço de pronto atendimento de Urgência e Emergência, demonstrado através de gráficos de controle. O monitoramento, do tempo de espera ajuda as unidades de saúde a melhorar a prestação de serviço junto à população. De uma forma mais clara é possível visualizar onde ocorre o maior problema da superlotação, portanto, o objetivo desta pesquisa é mostrar o uso do (CEP) nas Unidades de Saúde, para diagnósticar falhas de superlotação e o aumento no tempo de espera, através da análise dos prontuários.

O Controle Estatístico de Processo (CEP) pode ser um método eficaz de diagnóstico das dificuldades no atendimento dos hospitais, que além, de demonstrar as variabilidades, podem apresentar também à causa raiz [2]. Numa abordagem que convenciona os gráficos para diagnósticar os turnos com maiores problemas no tempo de espera, sendo usados para ilustrar o desempenho de cada turno assim, podendo proporcionar uma melhoria no atendimento dos usuários nos serviços de Unidades Hospitalares Públicas.

A pesquisa se pautou em trazer a importância da utilização do CEP no tempo de espera no atendimento em uma Unidade Hospitalar Pública de Urgência e Emergência, para diagnosticar os horários com maior problema. Com resultados comparativos do momento das dificuldades de atendimento, em que se consegue estabelecer uma melhoria com a diminuição dessa espera colocando-o sob controle confirmando o impacto no processo de atendimento da Unidade Hospitalar Pública de Urgência e Emergência com a aplicação do CEP.

A aplicação do CEP nas cartas de controle do atendimento aos usuários da unidade hospitalar de urgência e emergência, permite trazer uma visão geral do tempo de espera, e se há pontos de inconsistência, proporcionando uma análise e diagnostico de como está o serviço prestado a população. Focando de forma pontual as falhas a serem solucionadas, lembrando que, o CEP é uma técnica que virtualmente consente avaliar o processo, manter o mesmo em condição de controle estatístico, para que se possa melhorar a qualidade do serviço ou produto. Resumindo-se na redução de variabilidade dos procedimentos.

O estudo do CEP no tempo de espera no atendimento dos usuários em uma Unidade Hospitalar Pública de Urgência e Emergência traz a importância de usar um controle através de métodos estatístico, para melhorar a qualidade do atendimento dos serviços de saúde.
Podendo ser aplicado em qualquer que seja o seguimento: indústria, agroindústria, comércio ou serviços privados ou públicos, tem bastante relevância não só para o atendimento das necessidades dos usuários dos problemas decorridos dos processos, trazendo uma melhoria na qualidade dos processos [3].

As empresas precisam estar continuamente na busca de estratégias inovadoras, para tornar-se sempre competitiva. É impossível para as organizações adaptarem-se continuamente as mudanças e obter sucesso sem que antes seja feita uma análise periódica de seu processo, através de aplicações de métodos que possam proporcionar uma visão geral dos pontos fortes, fracos e a melhorar. O CEP é uma ferramenta que possibilita trazer um parâmetro de como os procedimentos estão sendo executados, focado nos pontos críticos do processo para uma ação corretiva mais eficaz. Essa ferramenta, quando aplicada corretamente, além de propiciar uma prestação de serviço com mais qualidade, contribui para melhorar os níveis de satisfação dos clientes, o que reflete diretamente na qualidade de vida da população.

O presente estudo tem por objetivo mostrar a eficiência da aplicação do Controle Estatístico de Processo no tempo de espera dos usuários de uma unidade hospitalar, para diagnosticar problemas nos processos de atendimento. O gráfico de controle é utilizado na detecção de alterações inusitada de uma ou mais características de um processo. É uma ferramenta estatística que desperta para a presença de causas especiais. As ferramentas de CEP demonstraram ser bastante eficazes para o controle de um serviço.

Em geral, o CEP é uma ferramenta de grande importância quando se permite avaliar as causas das variações nos índices de um processo, proporcionando a aplicação de soluções para as mesmas. A Utilização do Controle Estatístico do Processo para o Monitoramento de um sistema serve de base tanto para decisões sobre todo o sistema.

O Controle Estatístico do Processo (CEP) vem sendo implantado em um número cada vez maior pelas organizações, visando à obtenção de melhorias contínuas para uma melhor satisfação dos clientes. O Controle Estatístico de Processo é mais que um controle total de qualidade, ele estimula as mudanças culturais nas organizações, que passa a ter enfoque principal na qualidade, atenção à variabilidade e trabalho em equipe.

Diante do exposto surgiu a seguinte problemática: $O C E P$ pode ser aplicado no tempo de espera no atendimento dos usuários em Unidades Hospitalar?

\section{REVISÃO BIBLIOGRÁFICA}

\section{II.1 CONTROLE ESTATÍSTICO DE PROCESSO (CEP)}

O Controle Estatístico do Processo (CEP) é um mecanismo que permite conhecer o processo, manter o mesmo em estado de controle estatístico, para que se possa melhorar a capacidade do mesmo. Tudo isto se resume à redução de variabilidade do processo [4]. O CEP pode ser aplicado em diversas áreas de uma organização, assim como, em instituições 
Rosimeire F. P. Oliveira, Sidney dos S. Oliveira / ITEGAM-JETIA Vol.02, Nº 07, pp.69-83. Setembro, 2016.

públicas que prestam serviços para a população. Tendo como papel principal analisar e demonstrar através de gráficos os pontos que fogem das normalidades de um procedimento ou processo.

Os gráficos de controle são utilizados com intuito de monitorar o processo e sinalizar aos analistas a necessidade de averiguar e ajustar conforme a necessidade da empresa, conforme o tamanho dos desvios encontrados. O controle do processo é o método preferido para controlar qualidade dentro do processo em vez de ser inspecionada no final. [5].

Verifica-se que, o CEP é um programa de investimento que tem seus custos escriturados e os benefícios previstos e medidos. Os gráficos de controle gerado pela aplicação do CEP proporcionam uma análise geral da situação dos processos, no caso dos prontuários de atendimento, podendo trazer fatos pontuais para uma aplicação de ação corretiva.

Nos últimos anos a Estatística é vista muito mais do que um ajuste de técnicas úteis para alguns campos fechados ou limitados da ciência, não é apenas um elemento da matemática onde se pesquisam os processos de aquisição, organização e diagnostico de dados sobre uma determinada população [6].

Assim como, não se acopla a um conjugado de informações numericamente relativas a um acontecimento social, nem a tabelas e gráficos usados para uma síntese, o arranjo e apresentação dos dados de uma pesquisa, embora este seja um aspecto da estatística que pode ser facilmente percebido no cotidiano, de forma que o CEP se torna um auxiliar nos diagnostico de problemas e soluções tanto de processos como de procedimento.

O CEP é um instrumento criado a partir de cálculos estatísticos, que representam o comportamento de uma determinada técnica, usadas para monitorar a variabilidade do processo e avaliar sua estabilidade. Ela nos permite apontar qual o tipo de variação que esta atuando no processo num apurado período. Isto caracterizará se o processo estará ou não sob controle estatístico [4].

O CEP tem como base inicial a coleta de dados seguindo com outros instrumentos utilizados pela qualidade. Através dessa coleta é possível realizar uma análise criteriosa sobre o que foi encontrado [7]. A importância da ferramenta pauta-se nas diversas aplicações que bem utilizada traz vantagens que tende a melhorar a qualidade do sistema da organização. Bem como, melhorar os procedimentos para que se possa ter uma qualidade nos serviços oferecidos. Através da análise do CEP pode-se ter, processos com menos variabilidade, com níveis de qualidade nos resultados finais. E surpreendentemente quando se fala em melhorar processos, isso significa que, não somente a melhorar a qualidade, mas também diminui os custos.

\section{II.1.1 VARIABILIDADE NO PROCESSO}

Dois produtos ou características nunca são exatamente iguais, decorrente de que, qualquer processo contém muitas fontes de variabilidade. As contestações entre produção podem ser grandes, ou elas podem ser infinitamente pequenas, mas elas estão sempre presentes.

Há três tipos de variação que podem ocorrer em um item produzido que são [8].:

a) Variação interna: ocorre dentro do próprio item;

b) Variação item a item: ocorre entre itens produzidos em tempos adjuntos;

c) Variação tempo a tempo: ocorre entre itens produzidos em períodos diferentes durante o dia.

O CEP é um instrumento utilizado para diagnosticar falhas de qualidade, de forma que é aplicado para monitorizar irregularidades no processo, com intuito de minimizar suas variações.

\section{II.1.2 CAUSAS DE VARIABILIDADE EM PROCESSOS}

As variações são consideradas como alterada pela natureza intrínseca do processo normal. Já as variações de causa específica são definidas como: variações anormais de processo, que são induzidas por atribuível provocado por fatores não conhecidos, que devem ser investigados [9]. As maiores causas de problemas no resultado final de um procedimento ou processo é decorrente das sazonalidades que faz com que um sistema se torne ineficiente ou deficitário.

$\mathrm{Na}$ estatística, a instabilidade do processo é manifestada por uma anomalia da variável $T B E$ em seu meio, a variabilidade ou distribuição, situações que podem ser detectados com um prontuário, para identificação do tempo de espera de um usuário [10]. O mecanismo estatístico proporciona uma visão geral do andamento do processo e seu comportamento, assim como, os pontos de falhas. Possibilitando de forma pontual ter um diagnóstico preciso dos pontos críticos, para possíveis ações corretivas mais eficientes.

\section{II.1.3 GRÁFICOS DE CONTROLE}

Os Gráficos de controle são algoritmos gráficos para monitorar e diagnosticar a atuação de um processo ao longo do tempo, detectando possíveis mudanças de grandeza nos valores nominais dos principais parâmetros; por exemplo, o desvio médio padrão ou de um desempenho variável descritiva. As adaptações dos gráficos são otimizadas para monitorar dados variáveis a partir de um processo, em um determinado momento em que a média pode ser desenhada para um grupo de produtos ou de serviços que correm.

No momento que passou a ser utilizada como instrumento do CEP para monitorar os processos e garantir a qualidade, o gráfico de controle tem sido cada vez mais adotado em todos os seguimentos e setores por trazer um parâmetro mais visível e pontual do problema [10]. No Brasil, o Controle Estatístico de Processo vem sendo implantado por um número crescente de entidades. Sendo que nas empresas públicas o CEP, é um tanto desconhecido, mas, que nos últimos anos os cursos voltados para a 
Rosimeire F. P. Oliveira, Sidney dos S. Oliveira / ITEGAM-JETIA Vol.02, Nº 07, pp.69-83. Setembro, 2016.

área pública tem abordado tal tema e sua eficiência dentro das entidades públicas.

Em várias indústrias, tais como as montadoras de veículos, utilizam a ferramenta em suas matrizes e em outras fábricas no exterior, sendo sua eficácia comprovada no monitoramento e redução de problemas [11].

Vale lembrar que todos os estudos realizados no âmbito do CEP envolvem medições e avaliações. Assim, é fundamental que o sistema de medição seja adequado [12].

De acordo com [13] ainda há muito por fazer em razão da potencialidade do Controle Estatístico de Processo não ter sido totalmente explorada. Novas aplicações aparecem diariamente, demonstrando a sua versatilidade e importância no aumento da competitividade.

\section{II.1.4 A INTERPRETAÇÃO DAS CARTAS DE CONTROLE UTILIZANDO O CEP}

As cartas de controle são documentos utilizados para registrar um procedimento. A aplicação do CEP nas cartas de controle traz um parâmetro de como está o andamento de um processo. Faz necessário seguir uma sequência de etapas para as análises das cartas de controle para que se tenha um diagnóstico mais eficiente.

\section{Conforme [14].:}

$>$ Etapa 1: Estabelecer limites de controle experimentais após a coleta de dados de acordo com o planejado para a amostragem;

> Etapa 2: Verificar se todos os pontos estão dentro dos limites de controle e se nenhum limite está em desacordo.

$>$ Etapa 3: Conferir se nos passos anteriores está tudo conforme os parâmetros estabelecidos, caso as duas condições forem satisfeitas, pode-se dizer que, o processo está sob controle estatístico, e o próximo passo é avaliar a capacidade do processo.

$>$ Etapa 4: $\mathrm{Na}$ ocorrência de haver pontos fora dos limites de controle e/ou algum parâmetro em desacordo, observa-se que, o processo está fora da condição de controle estatístico. Nesta ocorrência, deve-se fazer um diagnostico para identificar as possíveis de incoerência em cada ponto.

> Etapa 5: Após a identificação das causas de não conformidade, esses pontos devem ser eliminados da amostragem e novos limites experimentais devem ser calculados e a análise. Esses passos devem ser executados até que se conclua que o processo está fora ou sob controle estatístico.

Ao cumprir cada etapa, ocorre uma diminuição das falhas ao analisar as cartas de controle, se os passos forem executados continuamente, podem restar poucos pontos para análise, o que diminui a representatividade do processo, para essa situação a solução é coletar novas amostras e reiniciar a análise.
Assinalar pontos fora dos limites de controle é uma atividade simples, porém, identificar configurações não-aleatórias é uma tarefa que gera muitas dúvidas e que requer uma pesquisa minuciosa, daí a utilização do CEP para tais dificuldades [15].

As unificações dos processos relativos às configurações não-aleatórias foram constituídas para promover a detecção de variações relativas a causas especiais e preparados a partir das características da distribuição normal, através de regras estatísticas relativamente simples.

Uma vez construída os gráficos de Controle, pode-se observar o comportando do processo durante um determinado período de tempo. Essas informações sobre a estabilidade do método permitem avaliar se o procedimento está SOB CONTROLE ou FORA DE CONTROLE.

\section{II.1.5 REPRESENTAÇÃO GRÁFICA ATRAVÉS DO HISTOGRAMA}

Histograma são representações gráficas através do molde de barra que desponta variações sobre uma faixa peculiar, e foi desenvolvido por Guerry em 1833, na qual descreve uma análise de dados sobre um problema, sendo aplicados para descrever os dados nas mais diversas áreas. É uma ferramenta que admite avaliar as propriedades de um processo ou um lote de produto oferecendo uma ampla visão da variante de um conjunto de dados.

Sendo utilizado para averiguação de processos fora da conformidade, determinado a disseminação dos valores de medidas como parâmetro de controle ou fora de controle, para aplicação de ações corretivas, para encontrar e mostrar através de gráfico o número de unidade por cada categoria e dá compreensão (

$$
\text { Histograma do ruído e função e aproximação }
$$

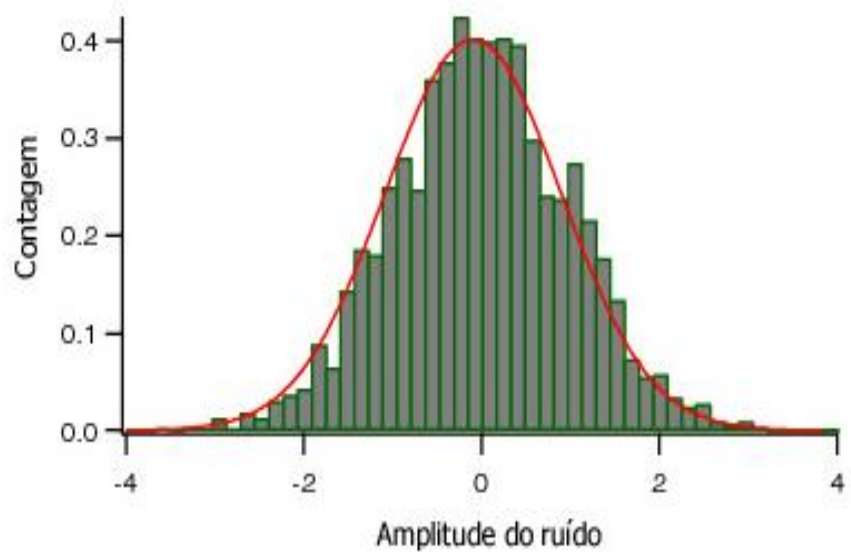

Figura 1 - Modelo de histograma.

Fonte: [17]. 
Rosimeire F. P. Oliveira, Sidney dos S. Oliveira / ITEGAM-JETIA Vol.02, Nº 07, pp.69-83. Setembro, 2016.

Uns dos requisitos básicos para elaboração de um histograma baseia-se primeiramente na Coleta de dados seguido dos cálculos dos parâmetros tais como amplitude "R", classe "K", frequiência de cada classe, média e desvio padrão.

Após a coleta de dados para se fazer histograma tem que [18]:

$>$ Obter os dados com número maior de trinta;

> Delimitar a amplitude "R": $\mathrm{R}=$ maior valor - menor valor;

$>$ Delimitar a classe "K";

$>$ Eleger o número da classe usando o entendimento $\mathrm{k} \approx \sqrt{\mathrm{n}}$ ou até mesmo determinar o intervalo da classe " $\mathrm{H}$ ". $\mathrm{H}$ $=\mathrm{R} / \mathrm{k} . \mathrm{R}=$ Amplitude (maior valor - menor valor);

$>$ Definir o limite da classe sendo o maior e o menor valor levantado na coleta de dados da amostra;

$>$ Definir a média de cada classe: soma do 1 imite superior + inferior dividido;

$>$ Definir a frequiência de cada classe. $\mathrm{Fr}=(\mathrm{F} / \mathrm{n}) \times 100$;

$>$ Produzir o gráfico, no eixo vertical à altura da classe com a frequiência calculada e no eixo horizontal o intervalo de cada classe.

\section{II.2 CÁLCULO DA MÉDIA}

A média em qualquer área de investigação onde números aparecem com frequência, podem ser expressos através de gráficos, que traz uma visão mais clara dos valores e percentuais. Por exemplo, o cálculo de uma tendência central é importante, por conseguir condensar uma série de dados em um único número. $\mathrm{E}$ se dá pela soma dos números de uma tabela divido pela quantidade dos números [19].

Foram feitos três médias do horário da manhã que vai das 6:00h as $11: 59 \mathrm{~h}$ conforme Tabela 1 , do horário da tarde que vai das 12:00h as 17:59h conforme Tabela 2, e do horário da noite que corresponde das 18:00h as 23:59h conforme Tabela 3, demonstrados nos Resultados Alcançados.

\section{II.2.1 CÁLCULOS DA MEDIDA DE VARIABILIDADE - DESVIO PADRÃO}

Para os Cálculos das medidas de variabilidade - desvio padrão - de acordo com [20] são as medidas de dispersão, sendo representado pelos elementos que se espalham ao redor da média. Quando os números são sempre próximos à média, significa que, a tendência central representa bem as informações, entretanto, quando alguns números ficam longe da média, há uma variabilidade nessa inspeção de dados.

A média do tempo de espera dos usuários da Tabela 1 foi calculado pela soma do tempo de espera em minutos dividido pela quantidade $\sum=\mathrm{TEM} / \mathrm{n}$.

O desvio ao redor da média é definido como a diferença entre um número individual e a média de todos os dados, desvio = $\left(X_{\mathrm{i}}-\overline{\mathrm{X}}\right)$.

As Tabelas 1, 2 e 3, mostram o desvio (na oitava coluna). Já (na nona coluna) mostra os valores que estão na oitava coluna, só que, sem o sinal do desvio, na qual é chamado de módulo ou valor absoluto do desvio, cuja a média do desvio da coluna 7 é soma dos números em minutos dividido pela quantidade de números $M e ́ d i a=\Sigma / n$. Já para o cálculo da amplitude se dá por Amplitude = xmáx-xmín, [21] .

Esta forma de medida de variação se baseia na diferença de cada elemento e a média da distribuição. A partir da ideia de que a média aritmética seria o valor que todos os dados teriam caso não houvesse variabilidade, portanto, a soma das diferenças de cada informação para a média representa o quanto às observações variam a partir da média.

Fora verificado que a soma algébrica dos desvios da média é igual à zero, o que impede o uso da simples soma dos desvios como medida de variabilidade. Uma forma de superar essa limitação é elevar cada desvio ao quadrado, uma vez que todos os quadrados terão valor positivo. A soma dos quadrados é então a soma dos quadrados dos dados em relação à respectiva média. É simbolizada por SQ e calculada da seguinte maneira:

$$
\mathrm{SQ}=\left(\mathrm{X}_{1}-\text { Média }\right)^{2}+\left(\mathrm{X}_{2}-\text { Média }\right)^{2} \ldots+\left(\mathrm{X}_{\mathrm{n}}-\text { Média }\right)^{2}
$$

De acordo com [19] para que possa ser resolvido o problema do sinal do desvio, é preferível utilizar o quadrado do desvio, também sem sinal todos somados como antes e a média deles calculada.

$$
\text { Desvio Padrão }=\sum_{\mathrm{i}=1}^{\mathrm{n}} \frac{\left(\mathrm{x}_{\mathrm{i}}-\overline{\mathrm{x}}\right)^{2}}{\mathrm{n}-1}
$$

Visto posto que, a média dos quadrados dos desvios chama-se no nome técnico de variância. De forma que, para se chegar à medida do desvio médio, faz-se necessário aplicar a raiz quadrada a variância. Demonstrado nas Tabelas 1, 2 e 3.

\section{II.2.2 CÁLCULOS DA TABELA DE FREQUÊNCIA}

Antes de calcular a tabela de frequência, deve-se encontrar a amplitude $\mathrm{R}$ (intervalo total) por meio da identificação do valor máximo e o valor mínimo para calcular a amplitude.

$$
\text { AT = XMÁX - XMÍN }
$$

Após isto, deve-se calcular o tamanho de classe ou intervalo pela fórmula $k=\sqrt{n}$, onde $\mathrm{n}$ são os números de atendimentos, e o valor de $\mathrm{k}$ deve ser um valor inteiro, podendo ser arredondado para maior ou para menor.

Depois, deve-se determinar a amplitude do intervalo, através da fórmula:

$$
h=\frac{R}{k}
$$

Sendo que, o valor da amplitude (R) se necessário, deve ser acrescido unidades para que sua divisão pelo número de classes seja um número inteiro.

Limites das Classes: São os números extremos das classes. E utiliza a seguinte representação: 
Rosimeire F. P. Oliveira, Sidney dos S. Oliveira / ITEGAM-JETIA Vol.02, No 07, pp.69-83. Setembro, 2016.

excluindo LSi )

LIi - - LSi (Compreende todos os valores de LIi a LSi,

LIi-LSi+h

Ponto Médio das classes (Xi): É a média aritmética entre o limite superior, denotado por LSi, e o limite inferior, denotado por LIi. O ponto médio será denotado por $\mathrm{Xi}$, onde $\mathrm{Xi}=(\mathrm{LIi}+\mathrm{LSi}) / 2$.

Frequência absoluta ou simples (Fi): É o número de observações que se encontra presente em uma classe ou intervalo específico, $\mathrm{Fi}=\mathrm{n}$.

Frequência simples acumulada (Faci): É a soma das freqüências simples das classes ou dos valores anteriores.

$$
\mathrm{Faci}=\mathrm{F} 1+\mathrm{F} 2+\ldots+\mathrm{Fi}
$$

Frequência percentual (fi\%): Representa o percentual de um certo valor na amostra.

$$
\mathrm{fi} \%=(\mathrm{Fi} / \mathrm{n}) \times 100 \quad \mathrm{fi} \%=100
$$

Frequência percentual acumulada (faci\%): É a soma das frequências relativo percentual das classes ou dos valores anteriores.

$$
\mathrm{faci} \%=\mathrm{f} 1 \%+\mathrm{f} 2 \%+\ldots+\mathrm{fi} \%
$$

\section{II.3 SAÚDE NO BRASIL}

Segundo a [22] a Saúde Pública é um direito de todos os Brasileiros conforme a Constituição Federal "Art $6^{\circ}$ - São direitos sociais a educação, a saúde, a alimentação, o trabalho, a moradia, o lazer, a segurança, a previdência social, a proteção à maternidade e à infância, a assistência aos desamparados, na forma desta Constituição" [22]. Assegurado no Art. $6^{\circ}$ da Constituição Federal de 1988, que todos os Brasileiros têm direito ao serviço de Saúde Pública independente da posição geográfica e social. É um direito e garantia de todos.

O conceito de Saúde há muito tempo vem sendo confundido com ausência de doenças. Porém, a doença é um estado causado pela falta de Saúde e de prevenção. Ser uma pessoa com Saúde é apresentar uma qualidade de vida nos termos sociais, físicos e psicológicos. Disfunções genéticas, síndromes, deficiências, ou até mesmo doenças incuráveis não servem para definir se o indivíduo possui ou não saúde.

Sobre a definição de Saúde a [23] diz no seu Artigo $3^{\circ}$ : "Os níveis de saúde expressam a organização social e econômica do País, tendo a saúde como determinantes e condicionantes, entre outros, a alimentação, a moradia, o saneamento básico, o meio ambiente, o trabalho, a renda, a educação, a atividade física, o transporte, o lazer e o acesso aos bens e serviços essenciais".
A [23], enxerga a Saúde como um indicador de qualidade de vida, quebrando o paradigma de que estar com Saúde é não estar doente. A Saúde está totalmente relacionada com a qualidade de vida da população, a prevenção de doenças é uma consequência quando se vive em um meio ambiente que priorize a saúde, e que favoreça a uma qualidade de vida excelente, sem esquecer também de cuidar do meio ambiente em que nos encontramos.

\section{II.3.1 SAÚDE PÚBLICA NO BRASIL}

Segundo a Constituição Federal de 1988 [22]: “Art. 196 A saúde é direito de todos e dever do Estado, garantido mediante políticas sociais e econômicas que visem à redução do risco de doença e de outros agravos e ao acesso universal e igualitário às ações e serviços para sua promoção, proteção e recuperação. Art. 197 - São de relevância pública as ações e serviços de saúde, cabendo ao Poder Público dispor, nos termos da lei, sobre sua regulamentação, fiscalização e controle, devendo sua execução ser feita diretamente ou através de terceiros e, também, por pessoa física ou jurídica de direito privado. Art. 198 - As ações e serviços públicos de saúde integram uma rede regionalizada e hierarquizada e constituem um sistema único, organizado de acordo com as seguintes diretrizes: I - descentralização, com direção única em cada esfera de governo; II - atendimento integral, com prioridade para as atividades preventivas, sem prejuízo dos serviços assistenciais; III - participação da comunidade".

Observa-se que, a Saúde Pública é toda a iniciativa e serviço prestado pelo governo brasileiro para proporcionar uma qualidade de vida, o combate e prevenção de doenças e a melhora da expectativa de vida da população, sendo assegurada pela Constituição Federal de 1988 como um direito que todos os brasileiros possuem.

De acordo com a [23]: “Art. 20 A saúde é um direito fundamental do ser humano, devendo o Estado prover as condições indispensáveis ao seu pleno exercício. $\S 1^{\circ} \mathrm{O}$ dever do Estado de garantir a saúde consiste na formulação e execução de políticas econômicas e sociais que visem à redução de riscos de doenças e de outros agravos e no estabelecimento de condições que assegurem acesso universal e igualitário às ações e aos serviços para a sua promoção, proteção e recuperação".

Pela [23], percebe-se que, o Estado tem a obrigação de promover a Saúde independente das adversidades encontradas pelo governo, sejam elas de locomoção, financeira, de instalações, ou social. O Estado precisa formular políticas para a promoção da Saúde e dos Serviços de Saúde.

Segundo [24]: "A visão da saúde entendida como ausência de doença é largamente difundida no senso comum, mas não está restrita a esta dimensão do conhecimento. Pelo contrário, essa ideia não só é afirmada pela medicina, como tem orientado a grande maioria das pesquisas e da produção tecnológica em saúde, especialmente aqueles referentes aos avanços na área de diagnóstico". 
Rosimeire F. P. Oliveira, Sidney dos S. Oliveira / ITEGAM-JETIA Vol.02, Nº 07, pp.69-83. Setembro, 2016.

No período em que o Brasil necessitou de uma melhora no Serviço de Saúde, o governo resolveu criar um plano para desenvolver o atendimento. A Estratégia Saúde da Família (ESF) surgiu no Brasil entre 1997 e 1999, quando o modelo de atendimento à população, não supria mais as necessidades de saúde da população [25].

A ESF foi uma nova organização dos planos de ações assistencial do governo. "Isto significa que o atendimento prestado pelos profissionais da ESF deve abranger não só o aspecto biológico do ser humano, mas também o psicossocial, realizando assistência centrada na pessoa ao invés da sua doença" [26].

Portanto, temos que pensar em vários fatores quando falamos de Saúde, como a moradia, nas condições de trabalho, na educação, na alimentação, na organização dos serviços de saúde, na preservação dos recursos naturais e do meio ambiente, na valorização das culturas populares, na participação popular e no dever do governo de melhorar as condições de vida do povo brasileiro [27].

\section{II.3.2 SISTEMA ÚNICO DE SAÚDE (SUS)}

Para atender a população o Governo criou o SUS [22]: “ Ao sistema único de saúde compete, além de outras atribuições, nos termos da lei: I - controlar e fiscalizar procedimentos, produtos e substâncias de interesse para a saúde e participar da produção de medicamentos, equipamentos, imunobiológicos, hemoderivados e outros insumos; II - executar as ações de vigilância sanitária e epidemiológica, bem como as de saúde do trabalhador; III - ordenar a formação de recursos humanos na área de saúde; IV - participar da formulação da política e da execução das ações de saneamento básico; V - incrementar em sua área de atuação o desenvolvimento científico e tecnológico; VI - fiscalizar e inspecionar alimentos, compreendido o controle de seu teor nutricional, bem como bebidas e águas para consumo humano; VII - participar do controle e fiscalização da produção, transporte, guarda e utilização de substâncias e produtos psicoativos, tóxicos e radioativos; VIII - colaborar na proteção do meio ambiente, nele compreendido o do trabalho".

Com a criação do SUS, o Governo visava melhorar o atendimento básico de Saúde da população brasileira, estabelecer controle sobre a criação de novos medicamentos, equipamentos e outros insumos, a execução de ações de vigilância sanitária, a fiscalização e inspeção dos alimentos e colaborar na proteção do meio ambiente.

O SUS foi criado pela [22], para que todos os brasileiros tivessem acesso ao atendimento público de saúde, já que antes da criação do SUS, a assistência médica ficava a cargo do Instituto Nacional de Assistência Médica da Previdência Social (INAMPS), o que restringia o atendimento apenas aos contribuintes da previdência social [27].

Para [28] o SUS tinha o pensamento de atendimento universalizado: "Com isso a proposta do Sistema Único de Saúde (SUS) apresentava como princípios norteadores universalidade de atendimento, a integralidade de ações e a participação popular inspirada na compreensão da saúde como direito do cidadão e dever do Estado".

\section{II.3.3 UNIDADE HOSPITALAR PÚBLICA}

Desde 2002, o Ministério da Saúde estabeleceu a Política Nacional de Atenção às Urgências, visto que, a demanda por esse tipo de serviço aumentou ultimamente no Brasil, com o aumento da violência e do número de acidentes. Os serviços Hospitalares existentes têm-se tornado insuficientes [29].

As equipes das Unidades Hospitalares de Saúde devem estar preparadas para as situações de urgência e emergência no atendimento. A superlotação dos prontos atendimentos, além de, provocar um óbvio desgaste, devido à sobrecarga de trabalho, causa ainda, um sentimento de descaso por parte dos usuários. Os hospitais costumam oferecer atenção básica, especializada e de urgência, na modalidade de pronto-atendimento, ou seja, atendimento imediato e de baixa resolutividade [30].

Observa-se a necessidade da qualidade nos serviços prestados à população, por meio da inclusão à máquina pública de serviços mais eficientes, resolutivos e afáveis, assim como a necessidade de reflexões, na busca da melhoria dos serviços prestados. A situação dos serviços de urgência e emergência é, hoje, motivo de preocupação para a comunidade sanitária e a sociedade em geral, e o seu uso tem sido crescente nos últimos anos [21].

Os serviços hospitalares são divididos em: Emergências em saúde são situações nas quais o atendimento não pode ser protelado, devendo ser imediato. Urgências em saúde são situações em que o atendimento pode ser prestado em tempo não superior a duas horas. Por fim, as situações não urgentes são definidas como aquelas que podem ser encaminhadas a um pronto atendimento ambulatorial, ou para o atendimento ambulatorial convencional [27].

O atendimento hospitalar no Brasil mostra deficiências estruturais do sistema de saúde, como: dificuldades de acesso ao atendimento, insuficiência de leitos, de médicos.

Nos últimos anos, a busca pela regionalização da assistência à saúde ganhou força no Brasil, com ênfase para a divulgação do Pacto pela Saúde [31].

É necessário avançar nas áreas prioritárias do Sistema Único de Saúde (SUS). Inclui-se, nesse intento, a concepção da Rede de Atenção às Urgências, haja vistas à articulação e integração de todos os aparelhamentos de saúde, ampliando e qualificando o acesso humanizado e integral dos usuários em situação de urgência e emergência, isso inclui o atendimento com mais rapidez [01].

A eficiência das redes de saúde de urgência e emergência pode estar relacionada à oferta de serviços articulados em diversos níveis de satisfação dos usuários. No entanto, essas unidades devem buscar mecanismo de melhoria que possa agilizar o processo, tornando-se mais eficaz os processos de atendimentos 
Rosimeire F. P. Oliveira, Sidney dos S. Oliveira / ITEGAM-JETIA Vol.02, Nº 07, pp.69-83. Setembro, 2016.

nessas unidades de saúde, com o intuito de evidenciar potencialidades e competências destes [17].

Os serviços hospitalares no SUS, tem como princípios a integralidade e a universalidade, implica na racionalidade entre o perfil epidemiológico e sanitário da população e a oferta de serviços e os orçamentos públicos, sem cominar em restrições injustificadas ou que comprometam o direito à saúde [27].

Percebe-se que, o aumento da demanda por tais serviços, tem pressionado a melhoria das as estruturas e dos serviços prestados de saúde e concebendo, por conseguinte, entre as principais causas de insatisfação da população que utiliza os sistemas de atenção à saúde [32].

Os aspectos referentes ao constante crescimento da demanda e ao desagrado dos usuários estão diretamente ligados à superlotação das unidades de urgência e emergência hospitalar e ao tempo de espera por tais serviços [33].

Ao avaliar o acesso aos serviços de urgência e emergência em unidades hospitalares, focados nos fatores que influenciam a entrada dos usuários nos serviços de saúde e, por consequência, a utilização destes, percebe-se um descaso com relação ao tempo de espera por parte dos usuários, que pode acarretar prejuízo para a saúde e até a morte dos que precisão de tais serviços [34].

Portanto, a compreensão da avaliação enquanto um conjunto dos serviços prestado tais como tempo de espera no atendimento pode ser melhorado, a partir do momento que se tem um diagnostico dos problemas ocorrentes. Com isso ao aplicar o CEP, a unidade consegue ter uma visualização mais clara da situação no tempo de espera e com isso aplicar melhorias que possa proporcionar uma maior satisfação por parte dos usuários desse serviço. Com vistas a um planejamento mais adequado à melhoria da qualidade das atividades oferecidas, também na perspectiva das necessidades e demandas dos usuários [35].

\section{II.3.3.1 URGÊNCIA E EMERGÊNCIA}

O Ministério de Estado da Saúde no uso da atribuição que lhe confere o inciso II do parágrafo único do art. 87 da Constituição, e considerando o disposto no art. 198 da [22], que estabelece que as ações e serviços públicos de saúde integram uma rede regionalizada e hierarquizada e constituem o Sistema Único de Saúde (SUS).

Com suas atribuições legais conferiu a Sistema Único de Saúde (SUS) as atribuições das Unidades Hospitalares Públicas de Urgência e Emergência, que fora regulamentada e através da portaria $\mathrm{n}^{\circ} 2.395$, de 11 de outubro de 2011, que organiza o Componente Hospitalar da Rede de Atenção às Urgências no âmbito do Sistema Único de Saúde (SUS).

As Unidades de Urgência e Emergência foram regulamentadas pela portaria $\mathrm{n}^{\circ} 2.395$, de 11 de outubro de 2011, que Organiza o Componente Hospitalar da Rede de Atenção às Urgências no âmbito do Sistema Único de Saúde (SUS) [1]: “ [...]
Considerando a Portaria $\mathrm{n}^{\circ}$ 1.600/GM/MS, de 7 de julho de 2011, que altera a Política Nacional de Atenção às Urgências e institui a Rede de Atenção às Urgências no SUS, com previsão expressa acerca do Componente Hospitalar, resolve: Art. $1^{\circ}$ Esta Portaria organiza o Componente Hospitalar da Rede de Atenção às Urgências no âmbito do Sistema Único de Saúde (SUS). Parágrafo único. A organização dar-se-á por meio da ampliação e qualificação das Portas de Entrada Hospitalares de Urgência, das enfermarias clínicas de retaguarda, dos leitos de Cuidados Prolongados e dos leitos de terapia intensiva, e pela reorganização das linhas de cuidados prioritárias de traumatologia, cardiovascular e cerebrovascular, de acordo com os critérios estabelecidos nesta Portaria. (Alterado pela PRT GM/MS n 2809 de 07.12.2012). Art. $2^{\circ}$ O Componente Hospitalar da Rede de Atenção às Urgências será estruturado de forma articulada e integrada a todos os outros componentes dessa Rede, a partir do Plano de Ação Regional, conforme Portaria n ${ }^{\circ}$ 1.600/GM/MS, de 7 de julho de 2011".

No Capítulo I, Art. $3^{\circ}$ da portaria $\mathrm{n}^{\circ} 2.395$, de 11 de outubro de 2011, foram regulamentadas os objetivos do componente Hospitalar da Rede e Atenção as Urgências [1]: "Art. $3^{\circ}$ : I - organizar a atenção às urgências nos hospitais, de modo que atendam à demanda espontânea e/ou referenciada e funcionem como retaguarda para os outros pontos de atenção às urgências de menor complexidade; II - garantir retaguarda de atendimentos de média e alta complexidade; procedimentos diagnósticos e leitos clínicos, cirúrgicos, de leitos de Cuidados Prolongados e de terapia intensiva para a rede de atenção às urgências; e (Alterado pela PRT GM/MS nº 2809 de 07.12.2012). III - garantir a atenção hospitalar nas linhas de cuidado prioritárias, em articulação com os demais pontos de atenção".

No Capítulo I, Art. $4^{\circ}$ da portaria $\mathrm{n}^{\circ} 2.395$, de 11 de outubro de 2011, foram regulamentadas as diretrizes do componente Hospitalar da Rede e Atenção as Urgências [1]: "Art. $4^{\circ}$. I - universalidade, equidade e integralidade no atendimento às urgências; II - humanização da atenção, garantindo efetivação de um modelo centrado no usuário e baseado nas suas necessidades de saúde; III - atendimento priorizado, mediante acolhimento com Classificação de Risco, segundo grau de sofrimento, urgência e gravidade do caso; IV - regionalização do atendimento às urgências, com articulação dos diversos pontos de atenção e acesso regulado aos serviços de saúde; e V - atenção multiprofissional, instituída por meio de práticas clínicas cuidadoras e baseada na gestão de linhas de cuidado".

Já no Capítulo II Art. $5^{\circ}$, Parágrafo $1^{\circ}$, desta mesma portaria, foram regulamentadas as portas de entrada hospitalares de urgência, segundo [1]: "Art. $5^{\circ}$ Para efeito desta Portaria, são Portas de Entrada Hospitalares de Urgência os serviços instalados em uma unidade hospitalar para prestar atendimento ininterrupto ao conjunto de demandas espontâneas e referenciadas de urgências clínicas, pediátricas, cirúrgicas e/ou traumatológicas. $\S 1^{\circ}$ Atendimento ininterrupto é aquele que funciona nas 24 (vinte e quatro) horas do dia e em todos os dias da semana".

Os serviços de saúde têm seu grau de prioridade nos atendimentos, conforme as definições abaixo [36]: 
Rosimeire F. P. Oliveira, Sidney dos S. Oliveira / ITEGAM-JETIA Vol.02, No 07, pp.69-83. Setembro, 2016.

- Urgência - É a ocorrência inesperada de agravo à saúde com ou sem risco possível de vida, cujo portador necessita de assistência médica imediata.

- Emergência - É a constatação médica de condições de agravo à saúde que impliquem em risco iminente de morte ou sofrimento intenso, exigindo, portanto, tratamento médico imediato.

- Atendimento Ambulatorial - É o serviço médico que deve prestar o primeiro atendimento à maioria das ocorrências médicas, tendo caráter resolutivo para os casos de menor gravidade e encaminhando os casos mais graves para um serviço de urgência e emergência ou para internamento hospitalar, para cirurgia eletiva ou para atendimento pelo médico especialista indicado para cada paciente.

Nos hospitais e prontos-socorros, observam-se placas com o enunciado Emergência. Entretanto, em vez de usar esse termo, alguns profissionais da saúde afirmam que determinado caso é urgente.

Em sumula os enunciados Emergência e Urgência são palavras parecidas, mas que, principalmente na área da saúde, as duas palavras exprimem conceitos totalmente diferentes, o que irá definir o tratamento de um paciente que acabou de chegar em uma instalação hospitalar. Usamos o termo emergência durante uma situação considerada crítica ou um perigo iminente, como um desmoronamento de terra, um incidente ou um imprevisto. $\mathrm{Na}$ área médica, quando a circunstância exige que ocorra uma cirurgia ou uma intervenção médica imediatamente, é um caso de emergência. Percebe-se que, as ambulâncias têm a palavra emergência, não urgência. Em um caso de urgência existe a necessita ser resolvida imediatamente, não pode ser adiada, pois, se houver demora, pode haver até risco de morte, no caso da área de saúde.

$\mathrm{Na}$ área médica, ocorrências urgentes precisam de um tratamento médico, até mesmo de uma cirurgia, mas podem apresentar também um caráter menos imediatista, por exemplo, um tratamento de câncer, que deve ser feito com urgência, mas não irá trazer as consequências de imediato.

Ainda assim, não deixa de ser um caso urgente. Diferente dos casos de emergência que necessitam de intervenção urgente, ou seja, não podem se prolongar. As diferenças no significado de urgência e emergência abrangem mais o campo científico. Por exemplo: certas hemorragias, paradas respiratórias e cardiovasculares são consideradas emergências.

Luxações, torções, fraturas (dependendo da gravidade, pois fraturas expostas, por exemplo, são consideradas extremamente graves e têm caráter emergencial) e doenças como dengue, catapora e sarampo são dotadas de um caráter mais urgente.

Para os Serviços de Saúde implica uma redução da eficiência, com maior dificuldade em dar respostas mais adequadas às necessidades reais da população.

\section{METODODOLOGIA}

A pesquisa é um diagnóstico através de um estudo de caso com o intuito de analisar a aplicação do CEP no tempo de espera em uma Unidade Hospitalar.

A pesquisa tem natureza qualitativa e quantitativa, buscando estabelecer relações entre o tempo de espera que são os quantitativos de controle com os pontos de variabilidades para investigar e comparar os pontos críticos correlacionando-os aos processos inerentes ao funcionamento de uma organização.

No que tange à finalidade da pesquisa, pode-se dizer que, o estudo se caracteriza como descritiva, por buscar descrever a correlação entre tempo de espera com o CEP aplicado para demonstração de variabilidade e o impacto advindo desta relação.

Os materiais utilizados para as aplicações do CEP foram os prontuários de atendimento das urgências em uma Unidade Hospitalar Pública de Urgência e Emergência na cidade de ApuíAM.

Foram usados também computador para a confecção do trabalho e software estatísticos para montagem dos gráficos.

\section{III.1.1 CARACTERÍSTICAS DA EMPRESA}

A investigação se caracteriza como uma pesquisadiagnóstico nos parâmetros de estudo de caso com o intuito de analisar aplicação do controle estatístico de processo no tempo de espera no atendimento dos usuários em uma Unidade Hospitalar Pública de urgência e emergência no município de Apuí no Estado do Amazonas, sendo que os dados foram coletados com relação ao atendimento de emergência durante os turnos matutino, vespertino e noturno no período de 10 a 15 de outubro de 2014.

A Unidade Hospitalar Pública possui 112 (Cento e doze) profissionais, 50 (cinquenta) usuários aproximadamente atendidos diariamente na Unidade Hospitalar que foi inaugurado no dia 08 de maio de 2004, atendimento 24 (vinte e quatro horas), de Leitos SUS: 40 (quarenta), com a missão de prover um atendimento às Urgências\ emergências e Internações, com tratamento de qualidade, segurança, humanizado e resolutivo, para todos os clientes que necessitam desse atendimento no Hospital Eduardo Braga. Visão: Ser instrumento imprescindível na gestão pública e na prestação de serviços à população.

A Unidade Hospitalar Pública fica localizada no município de Apuí, que em 30.12.1987, pela Lei $\mathrm{n}^{\circ} 1.826$ de $30 \backslash 12 \backslash 1987$ a área do Município de Novo Aripuanã foi emancipada, passando a constituir o novo Município de Apuí. Área Territorial: $53.040 \mathrm{Km}^{2}$; População: 18.633 - Senso IBGE/2012; Distância: em linha reta, entre Apuí e a capital do estado, $460 \mathrm{Km}$;

Os dados foram coletados durante os dias 10 a 15 de outubro de 2014, junto a Unidade Hospitalar Pública de Urgência de Emergência, sendo avaliada as fichas de pronto atendimento de urgência. Os dados coletados foram de 149 atendimentos no 
período de cinco dias que servirá como amostragem para os cálculos do Controle Estático de Processo. Para [20], planejar um gráfico de controle, é preciso estabelecer o tamanho da amostragem e a frequência da amostragem.

\section{APRESENTAÇÃO DOS RESULTADOS}

Após a aplicação do CEP nas cartas de controle pode-se observar que, não obedeciam aos parâmetros do histograma. Em posse dessa observância foi feito um levantamento das cartas de controle para descobrir o que provocou a variação inesperada e constatou-se que, utilizavam o mesmo prontuário para a entrada tanto de pessoas adultas, quanto de crianças e prioridades. Causando assim uma não conformidade nos gráficos de controle.

Constatando-se que, as cartas de controle não estão sendo usadas de forma correta, conforme os procedimentos da instituição, pois, devem-se ter um controle de prontuário separadamente os adultos, as crianças e as prioridades, além das emergências que devem ter prontuário próprio. gere-se uma ação corretiva, para que possa evitar problemas futuros com as junções dos tipos de pacientes em uma única carta de controle. Pelo fato de que causa uma inconsistência nas cartas de controle. Como o objetivo da pesquisa está no tempo de atendimento dos usuários da Unidade Hospitalar, foi utilizado apenas os atendimentos dos pacientes adultos, dessa forma foi retirado os atendimentos de crianças e prioridades. Para que o objeto de estudo que é a aplicação do CEP no tempo de espera possa ter um resultado mais preciso.

\section{IV.4.1 GRÁFICOS DAS FIGURAS DAS CARTAS DE CONTROLE DO TURNO DA MANHÃ}

Conforme o gráfico da figura 1, observa-se um gráfico linear, sendo que o atendimento após as $10 \mathrm{hs}$. Em decorrência do início do atendimento ser próximo ao horário do meio dia, os pacientes da manhã adentram ao horário da tarde.

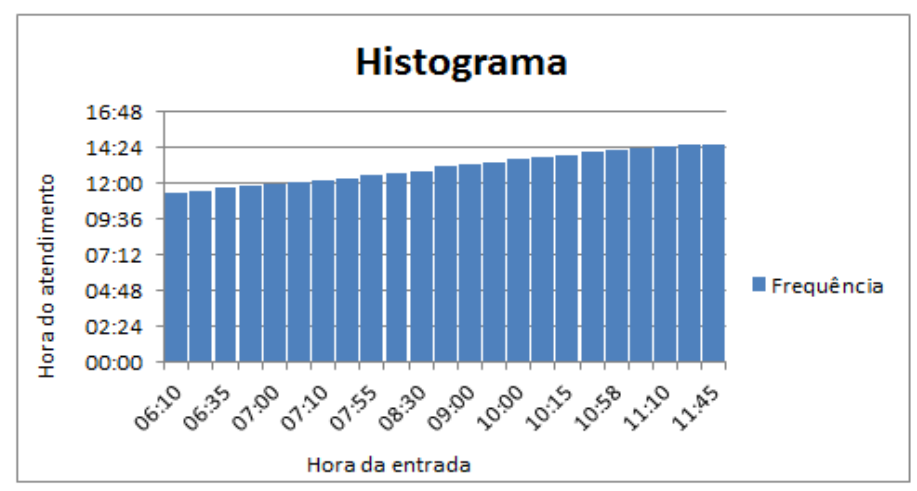

Figura 1: Gráfico da hora do atendimento dos usuários adultos no turno da manhã.

Fonte: Os autores, (2016).

O Gráfico da figura 2, mostra o tempo de espera dos usuários adultos, observa-se que, os pacientes que dão entrada após o horário das $10 \mathrm{hs}$, o tempo de espera diminui, já os usuários que chegam antes tem um maior tempo de espera. A diminuição vem em decorrência de que, após as 10hs, inicia-se o atendimento, e o paciente que chega a Unidade Hospitalar antes das $10 \mathrm{hs}$, tem que esperar o início do atendimento. O maior tempo de espera é de 5:10hs e o menor é de 2:55hs.

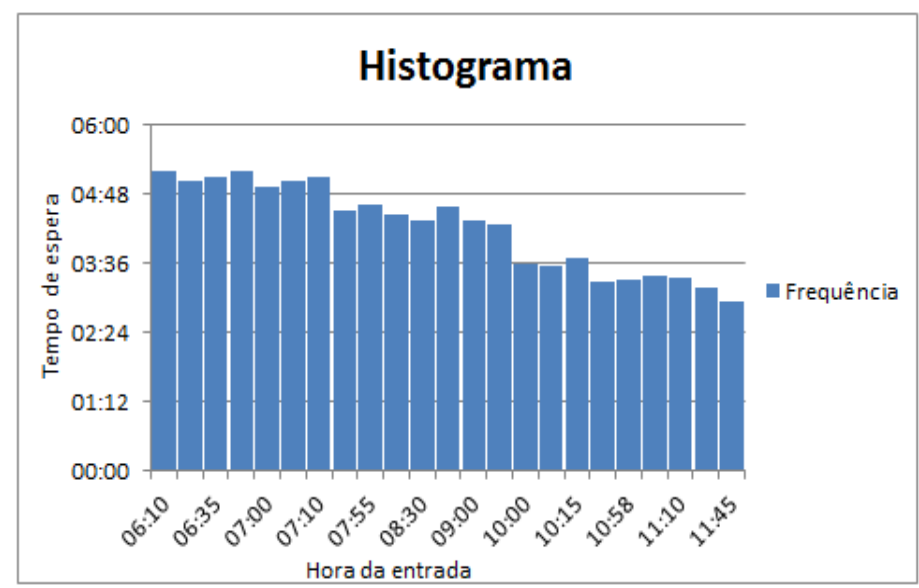

Figura 2: Grático do tempo de espera dos usuários adultos no turno da manhã.

Fonte: Os autores, (2016).

No Gráfico da figura 3, observa-se que, a maior frequência está no tempo de espera que vai de 3:49hs a 4:16hs, com uma frequência de 6 pacientes.

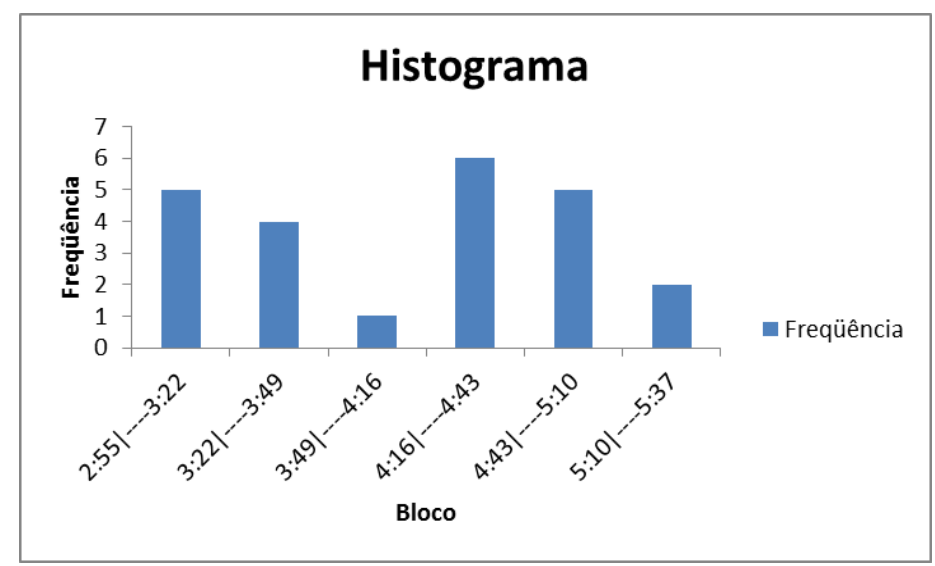

Figura 3: Gráfico da frequência no intervalo de classe em horas no turno da manhã

Fonte: Os autores, (2016).

\section{IV.4.2 GRÁFICOS DAS CARTAS DE CONTROLE DO TURNO DA TARDE}

Conforme o Gráfico da figura 4, observa-se um gráfico linear, sendo que o atendimento se inicia após as $14 \mathrm{hs}$. Em decorrência do início do atendimento do turno da manhã começar as $10 \mathrm{hs}$, fazendo com que os usuários do turno da manhã venham adentrar no turno da tarde para serem atendidos, prejudicando assim o turno da tarde, que só inicia após o encerramento dos pacientes da manhã. 


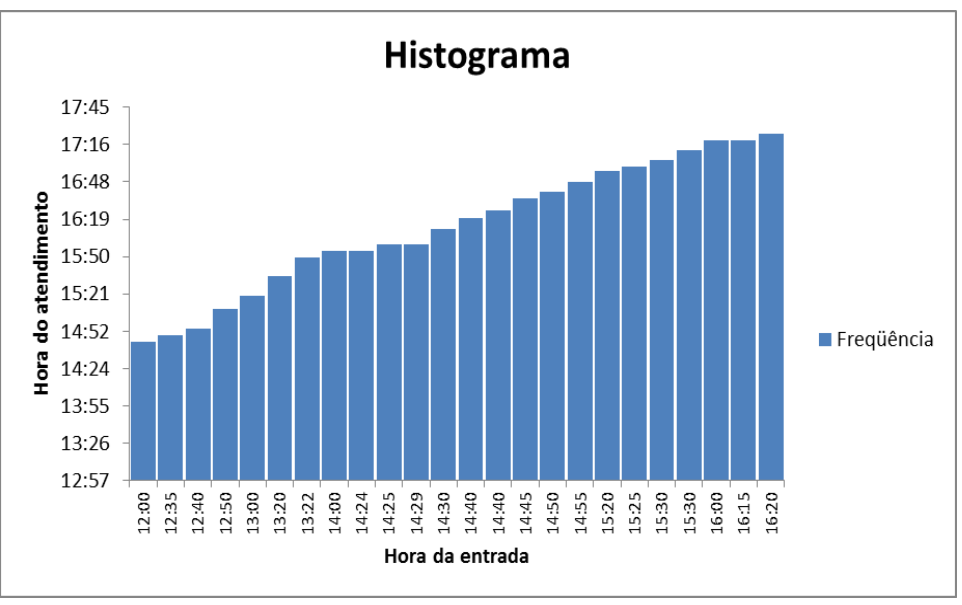

Figura 4: Gráfico da hora do atendimento dos usuários adultos no turno da tarde.

Fonte: Os autores, (2016).

O Gráfico da figura 5, mostra o tempo de espera dos usuários adultos, observa-se que, os pacientes que dão entrada no turno da tarde têm um tempo de espera menor que os usuários que dão entrada no turno da manhã antes das $10 \mathrm{hs}$.

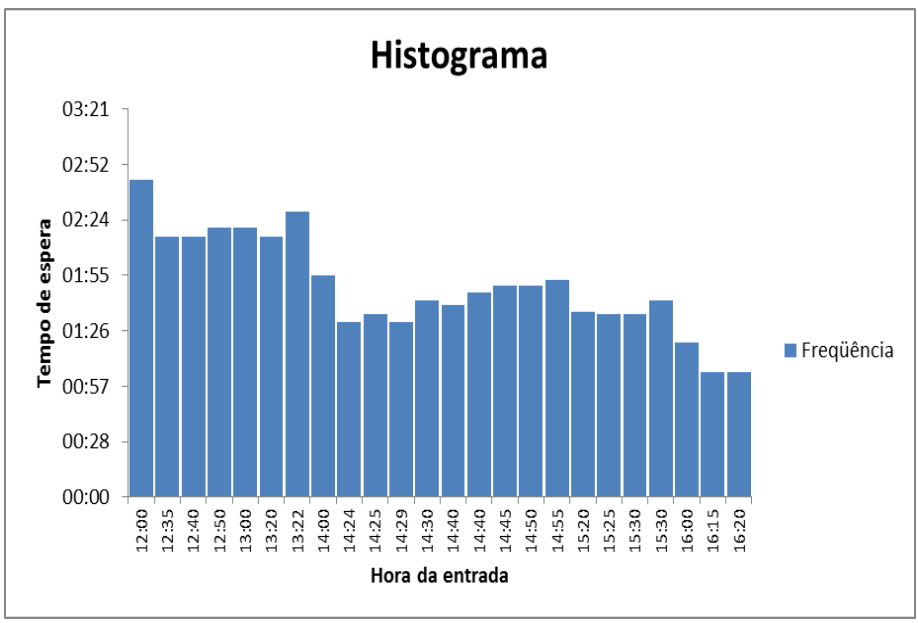

Figura 5: Gráfico do tempo de espera dos usuários adultos no turno da tarde.

Fonte: Os autores, (2016).

O tempo de espera vai diminuindo quando se aproxima das $16 \mathrm{hs}$, decorrência de que, após as $14 \mathrm{hs}$ encerra o atendimento dos usuários do turno da manhã, e já findando o turno da tarde o atendimento começa a se normalizar. Com o maior tempo de espera de 2:45hs e o menor 14 minutos.

No Gráfico da figura 6, observa-se que, a maior frequência está no tempo de espera que vai de 1:29hs (129 min) a 1:54hs (114min), com uma frequência de 13 pacientes.

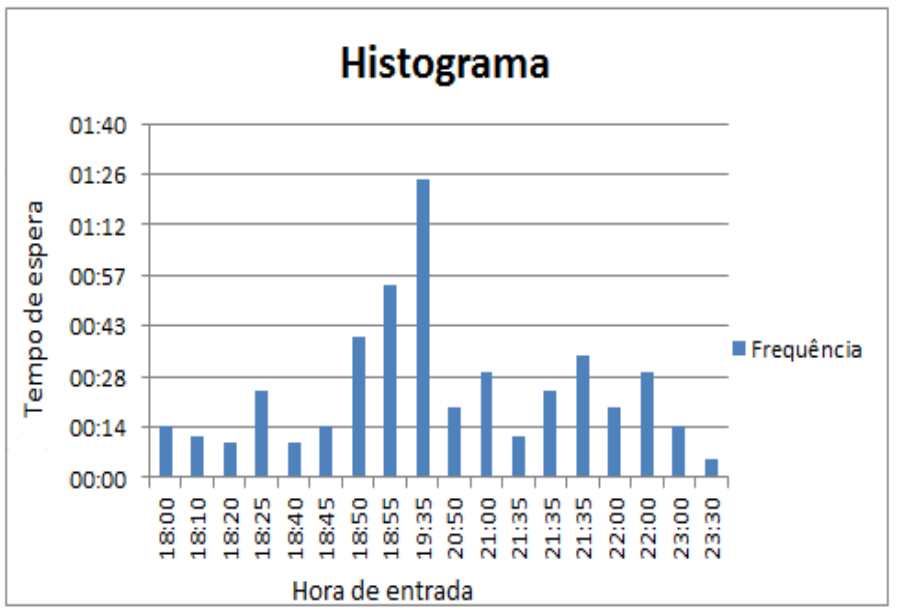

Figura 6: Gráfico da frequência no intervalo de casse em horas no turno da tarde.

Fonte: Os autores, (2016).

\section{IV.4.3 GRÁFICOS DAS CARTAS DE CONTROLE DO TURNO DA NOITE}

Conforme o Gráfico 7, observa-se um gráfico linear, sendo que o atendimento inicia-se após as $18 \mathrm{hs}$. $\mathrm{O}$ atendimento na Unidade Hospitalar no turno da noite inicia-se no horário normal.

Conforme o Gráfico da figura 7, observa-se um gráfico linear, sendo que o atendimento inicia-se após as $18 \mathrm{hs}$. O atendimento na Unidade Hospitalar no turno da noite inicia-se no horário normal.

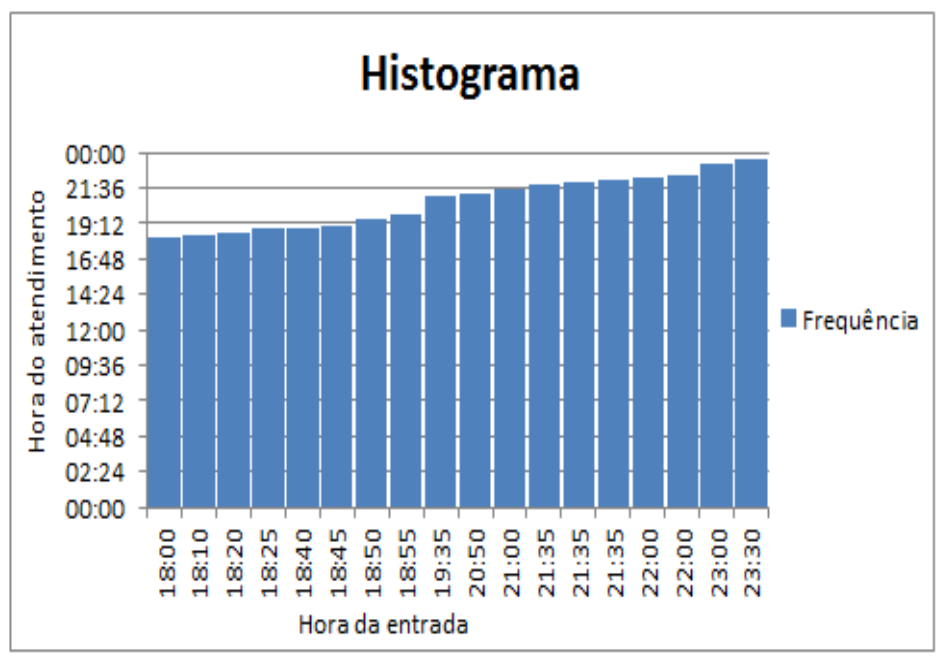

Figura 7: Gráfico da hora do atendimento dos usuários adultos no turno da noite.

Fonte: Autores, (2016).

O Gráfico da figura 8, mostra o tempo de espera dos usuários adultos, observa-se que, o atendimento obedece o tempo 
Rosimeire F. P. Oliveira, Sidney dos S. Oliveira / ITEGAM-JETIA Vol.02, Nº 07, pp.69-83. Setembro, 2016.

de atendimento em unidade de urgência. O tempo máximo de espera é de 1:15 h e o tempo mínimo 5 minutos.

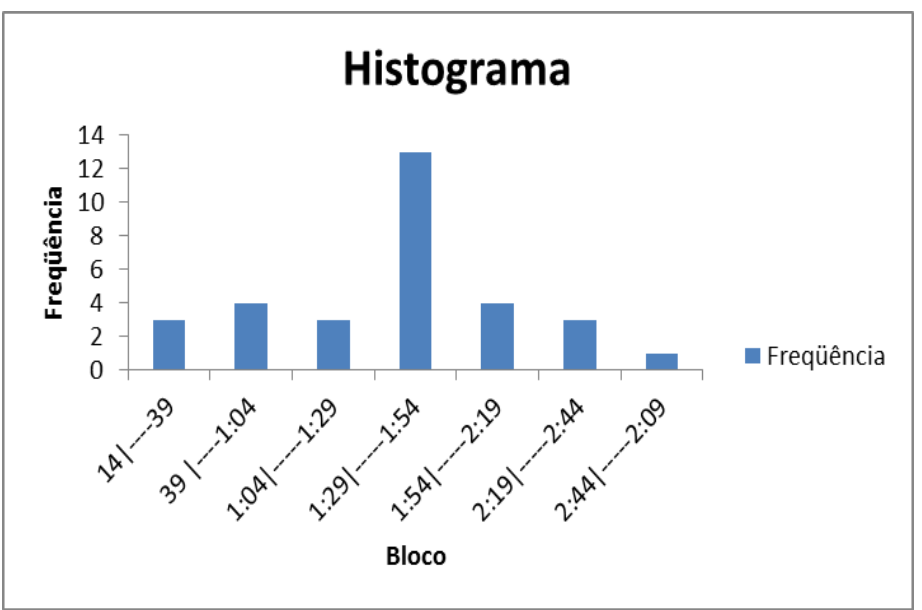

Figura 8: Gráfico do tempo de espera dos usuários adultos no turno da noite

Fonte: Os autores, (2016).

No Gráfico da figura 9, observa-se que, a maior frequência está no tempo de espera que vai de 5 a 25 minutos, com uma frequência de 10 pacientes.

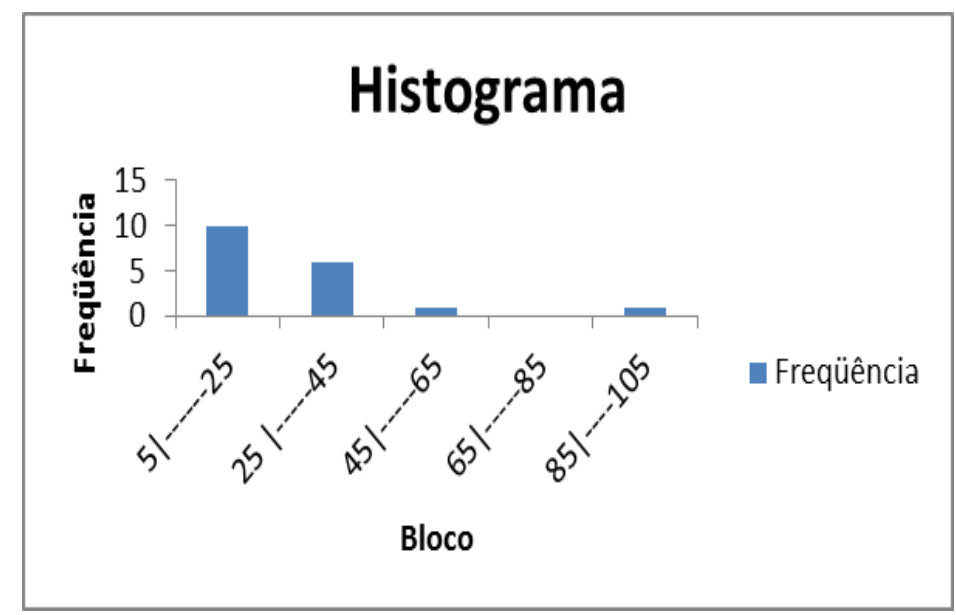

Figura 9: Gráfico da frequência no intervalo de casse em horas no turno da noite.

Fonte: Os autores, (2016).

\section{ANÁLISE DOS RESULTADOS}

O CEP proporciona uma melhor visualização $\mathrm{e}$ diagnóstico de um processo, auxiliando assim na aplicação de mecanismo corretivo pontual e preciso.

Após aplicar o CEP nas cartas de controle do atendimento na Unidade Hospitalar de saúde, pode-se ter um parâmetro de como está o atendimento no hospital.
Através do gráfico de controle, pode-se observar que, existe um tempo de espera muito elevado no turno da manhã e tarde, sendo que o mesmo não ocorre no turno da noite.

E que os atendimentos no turno da manhã só ocorrem após o horário das $10 \mathrm{~h}$. Como os médicos só atendem após as $10 \mathrm{~h}$, acumula-se uma grande quantidade de pacientes para serem atendidas, e que a espera entra no horário da tarde. Já os usuários que deram entrada no horário da tarde têm que esperar finalizar os atendimentos dos pacientes do turno da manhã, para que se possa iniciar o atendimento. O atendimento só normaliza após as $18 \mathrm{hs}$, fato observado no gráfico do turno da noite. Que o tempo de espera fica em média 30 minutos, limite aceitável para uma unidade de urgência. Decorrente de que, nesse horário os atendimentos já se encontrar normalizados.

Após um diagnóstico proporcionado pela aplicação do CEP, pode observar os problemas pontuais para investigação da causa raiz.

E a principal causa raiz veio decorrente do horário de atendimento do turno da manhã, conforme Gráfico 1 que mostra claramente o horário do início do atendimento dos pacientes que deram entrada no turno da manhã e o tempo de espera.

Em decorrência desse atraso os atendimentos entram pelo turno da tarde que por sua vez só inicia após o termino dos usuários que deram entrada pelo horário da manhã. Portanto, os usuários da tarde que dão entrada no horário das $12 \mathrm{~h}$, só vão ser atendido a partir das 14:40h, conforme observado no Gráfico 4.

No Gráfico da figura 7, percebe-se que, os atendimentos do turno da tarde terminam antes das $18 \mathrm{~h}$, observando que conforme se aproxima do término do turno da tarde o tempo de espera diminui, decorrente de que, a grande concentração que antes tinha vai diminuindo gradativamente.

Assim como no Gráfico 8, já com o atendimento normalizado observa-se que, o tempo de espera fica em média 30 minutos de espera, considerável aceitável para uma urgência, decorrente de que, já foi normalizado a demanda ocasionado pelo atraso nos atendimentos no turno da manhã.

Portanto, a causa raiz do tempo de espera dos usuários da Unidade Hospitalar de Urgência e emergência está no atraso do atendimento no turno da manhã. Por ser um hospital deveria ter médicos plantonistas $24 \mathrm{hs}$, só que está tendo médico somente a partir das $10 \mathrm{hs}$, causando assim todo um atraso nos atendimentos dos usuários que dão entrada na Unidade Hospitalar durante o dia, normalizando somente no turno da noite.

Após investigação do motivo dos médicos só atenderem a partir das $10 \mathrm{~h}$, foram constatados os seguintes fatos:

- O município conta com apenas três médicos clinico geral para atender toda rede de saúde.

- Os médicos consultam nos postos de saúde, no horário das $6 \mathrm{~h}$ as $10 \mathrm{~h}$, sendo que ambos atendem como plantonistas na 
Rosimeire F. P. Oliveira, Sidney dos S. Oliveira / ITEGAM-JETIA Vol.02, Nº 07, pp.69-83. Setembro, 2016.

Unidade Hospitalar, fato este o motivo de que o atendimento só inicia após as $10 \mathrm{~h}$.

- O hospital por sua vez conta apenas com um médico plantonista por dia, causando assim, mais atraso.

Outra observação foi de que, o controle de atendimento, é o mesmo para todos os grupos (emergência, prioridades, crianças e adultos), entretanto na hora de chamar na ordem os atendentes dão enfase primeiro para as prioridades seguido das crianças e depois os adultos e vão sem chamado em intervalo dos três grupos anteriores.

Sendo que, um adulto que chegou as 6h da manhã vai ser atendido após as prioridades e crianças. Isso causa uma demora na espera dos pacientes adultos, maior do que se tivesse um médico para atender as crianças.

Nesse estudo, pode-se mostrar que o CEP pode trazer as falhas no processos que após a análise e investigação das causas, pode diagnósticar que:

- O hospital não conta com um médico pediatra, e apenas um plantonista que por sua vez tem que atender a todas as demandas;

- O atendimento só inicia após as $10 \mathrm{~h}$, fazendo com que no horário da manhã acarrete um atraso de 4 horas para quem chegar as 6hs. Sendo que uma Unidade de Urgência deveria funcionar as $24 \mathrm{hs}$. Esse atraso nos atendimentos são decorrentes de que os médicos plantonistas, fazem primeiramente atendimento nos postos de saúde, para depois ir para a Unidade Hospitalar.

- Em decorrência do atendimento na Unidade Hospitalar só iniciar as $10 \mathrm{hs}$, acarreta um atraso tanto no turno da manhã como da tarde, pois, os pacientes do horário da manhã adentram no horário da tarde, e por sua vez, os pacientes do turno da tarde só vão ser atendidos após o encerramento dos usuários da manhã, decorrente de haver apenas um médico por plantão na Unidade Hospitalar, sendo que não há pediatra e nem médico plantonista para atender as emergências, sobrecarregando o médico de plantão que tem que atender a todas as demandas .

- Outro fato observado foi que as cartas de controle não são separadas de forma adequada, Emergência, Prioridades, Crianças e Adultos, prejudicando assim as análises da eficiência na prestação do serviço.

Portanto, o CEP pode trazer um parâmetro da situação do hospital, que além de, proprocionar um diagnóstico do processo trouxe de forma eficaz a causa raizes. Para que possíveis melhorias possam ser aplicadas.

Sugere-se que o hospital contrate mais médicos e possa fazer uma escala mais eficiêntes, com pediátras, médico para urgência e médico para emergência e que o atendimento possa ser iniciado as 6hs da manhã.

Pois o horário da noite e pela madrugada o atendimento encontra-se sobre controle, o tempo de espera está dentro das normalidades das urgência de até 2 horas para casos sem risco de morte.
Que o setor de atendimento possa separar as cartas de controle por grupos de pacientes sendo: Emergência, Urgência (prioridades, crianças e adultos). Para que a Unidade Hospitalar possa ter um parâmetro mais preciso da qualidade no atendimento.

\section{CONCLUSÃO}

Este estudo de caso apresentou as etapas desenvolvidas durante a implantação do Controle Estatístico de Processo em uma Unidade Hospitalar Pública no Município de Apuí-Amazonas.

Após a aplicação do CEP com a análise do controle do processo no tempo de espera do atendimento nos horários da manhã, tarde e noite. Pode-se verificar que, os usuários tem levado um tempo de espera maior do que permitido pelas diretrizes de uma unidade de Urgência que é de no máximo 120 minutos para casos sem risco de morte. E que, de acordo com os resultados, os serviços na Unidade Hospitalar de urgência não estão atendendo os usuários de maneira eficiente, trazendo assim muitos prejuízos para os usuários.

Salienta-se que, possa haver mais pesquisas que vise à melhoria dos procedimentos nas Unidades Hospitalares de todo o Brasil, para que a população possa ter suas necessidades atendidas por meio dos serviços públicos com presteza.

Sugere-se que, ações sejam tomadas sobre as causas identificadas para reduzir a variabilidade do processo no atendimento, e que a secretaria de saúde possa contratar profissionais que possam atender nos horários de maior demanda de pacientes. Para que os cidadãos verdadeiramente contarem com os serviços de urgência.

Nesse estudo, pode-se verificar a eficiência da aplicação do CEP nos serviços públicos. Mostrando assim que, o CEP pode ser aplicado nas unidades públicas hospitalares, e que proporciona um diagnostico eficiente dos problemas e causa raiz.

Portanto, o CEP mostrou sua utilidade ao ser aplicado no tempo de espera dos usuários em Unidade Hospitalar pública de Urgência e Emergência de forma eficiente e eficaz, podendo ser estendido para outros setores.

\section{AGRADECIMENTOS}

Ao Instituto de Tecnologia e Educação Galileu da Amazônia (ITEGAM), ao PPGEP do Instituto de Tecnologia Universidade Federal do Pará (ITEC-UFPA).

\section{REFERÊNCIAS}

[1] BRASIL. Ministério da Saúde. Portaria No 1.600, de 7 de julho de 2011. Reformula a Política Nacional de Atenção às Urgências e institui a Rede de Atenção às Urgências no Sistema Único de Saúde (SUS).

[2] OLIVEIRA, Sidney dos Santos.; LEITE, Jandecy C.; SOUZA, José A. da S., OLIVEIRA, Rosimeire Freires Pereira. Uso do 
Rosimeire F. P. Oliveira, Sidney dos S. Oliveira / ITEGAM-JETIA Vol.02, No 07, pp.69-83. Setembro, 2016.

Controle Estatístico de Processo (CEP) na gestão de operações produtivas em uma indústria no Polo Industrial de Manaus. Revista SODEBRAS. Volume $10 \mathrm{~N}^{\circ} 117$ de julho/2015.

[3] EDQUIST, Charles. Innovation Policy Design: Identfication of Systemic Problems. Circle. Lund University. Sweden. 2011.

[4] ROCCO, J. Perla; LLOYD, P. Provost; SANDY, K. Murray; The run chart: a simple analytical tool for learning from variation in healthcare processes; BMJ Qual Saf, 20: 46-51. 2011.

[5] REYNOLDS Jr., M.R., LOU, J.Y., An evaluation of a GLR control chart for monitoring the process mean. Journal of Quality Technology 42. 287-310. 2010.

[6] MATSUSHITA, R. Y. O que é estatística? 2010. Disponível em: <http://vsites.unb.br/ie/est/>. Acesso. 26/03/2016.

[7] MACHADO, José Fernando. Método Estatístico: Gestão de Qualidade para Melhoria Continua. São Paulo: Saraiva, 2010.

[8] CHENG, Zhi-Qiang, Yi-Zhong, Bu Jing, Song Hua-Ming. Mean Shifts Diagnosis And Identification In Bivariate Process Using Ls-Svm Based Pattern Recognition Model. International Journal Of Industrial Engineering. 20(7-8), 453-467. 2013.

[9] SAMOHYL, R. W.; HENNIN, E.; WALTER, O. M. F. C.; COSTA, R. N. Aplicações na Engenharia de Produção voltadas ao Controle Estatístico da Qualidade com o RExcel. Produção em foco artigo, Centro Universitário Tupy - UNISOCIESC Joinville. Santa Catarina. Brasil - ISSN 2237-5163 / v. 03. n. 01: p. 144-162. ano 2013.

[10] ZHOU, W., LIAN, Z., Optimum design of a new VSS-NP chart with adjusting sampling inspection. International Journal of Production Economics. 129. 8-13. 2011.

[11] PALLADINI, Edson Pacheco; et tal.; Gestão da Qualidade: Teoria e Casos. 2. Ed. São Paulo: Atlas, 2010.

[12] OWEN, M. Statistic Procees Control and Continuous Improviment. IFS Publication. USA, 1989.

[13] RAMOS, A. W. Controle Estatístico de Processos (CEP) para Processos Contínuos e em Bateladas. São Paulo: Edgard Blucher, 2000.

[14] WERKEMA, Maria Cristina Catarino. Ferramentas estatísticas básicas para o gerenciamento de processos. Belo Horizonte: Werkema, 2006.

[15] ALIVERDI, R., MOSLEMI NAENI, L., SALEHIPOUR, A., Monitoring project duration and cost in a construction project by applying statistical quality control charts. Int. J. Proj. Manag. 2013. 411-423.

[16] WERKEMA, Maria Cristina Catarino. Avaliação de sistemas de medição. 2.ed. Belo Horizonte: Werkema. 2012. $111 \mathrm{p}$.
[17] SAMOHYL, R. W. Controle Estatístico da Qualidade. Rio de Janeiro: Campus, 2009.

[18] CÉSAR, Francisco I. Giocondo. Ferramentas Básicas da Qualidade: Instrumento para gerenciamento de processo e melhoria contínua. $1^{\mathrm{a}}$ ed. Biblioteca 24 horas. Março 2011. <www.biblioteca24horas.com>. Acesso em 06 de maio de 2016.

[19] SAMOHYL, R. W. Controle Estatístico de Processo e Ferramentas da Qualidade. In: MONTEIRO, M. (Coord.) Gestão da Qualidade, teoria e caso. Rios de Janeiro: Editora Elsevier, Campus, 2006.

[20] MONTGOMERY, Douglas; RUNGER, George. Estatística Aplicada e Probabilidade para Engenheiros. 4 ed. Rio de Janeiro: Livros Tecnicos e Cientificos Editora S.A. 2009.

[21] MARSHALL Jr., I.; CIERCO, A. A.; ROCHA; A. V.; MOTA, E. B.; LEUSIN, S. Gestão da qualidade. 9. ed. Rio de Janeiro: editora FGV, 2008.

[22] BRASIL. Constituição (1988). Constituição da República Federativa do Brasil : 1988 - texto constitucional de 5 de outubro de 1988 com as alterações adotadas pelas Emendas Constitucionais de n. 1, de 1992, a 53, de 2006, e pelas Emendas Constitucionais de Revisão de n. 1 a 6, de 1994. 27. ed. - Brasília : Câmara dos Deputados, Coordenação de Publicações, 2007.

[23] Lei 8.080, de 19 de novembro de 1990.

[24] BATTISTELA, Carlos; Abordagens contemporânea do conceito de Saúde. O Território e o Processo Saúde-Doença. Rio de Janeiro: EPSJV/Fiocruz, 2007. p. 51-86.

[25] ROSA, W.A.G; LABATE, R.C. Programa Saúde da Família. A construção de um novo modelo de assistência. Revista Latina Americana Enfermagem[S.I], v.13, n.6, p. $1027-$ 1034, Nov/Dez.2005.

[26] MACIEL, M. E. A equipe de saúde da família e o portador de transtorno mental: relato de uma experiência. Cogitareenferm.2008. Jul/Set;

[27] BRASIL, Ministério da Saúde. Secretária de Atenção à Saúde. Departamento de Atenção Básica. O trabalho do agente comunitário de saúde. Brasília, 2009.

[28] OLIVEIRA, A. K. N.; BORGES, D. F. Programa de Saúde da Família uma avaliação de efetivada com base na percepção do usuário. Revista de Administração Pública. Rio de Janeiro, V.42, n.2, p69-89 mar/abr.2008.

[29] SÁ D.A. Proposta metodológica para classificação dos hospitais de urgência/emergência do SUS. Brasília: Secretaria Executiva, Ministério da Saúde; 2005.

[30] CALIL AM. O enfermeiro e as situações de emergência. São Paulo: Atheneu. 2007. 
[31] BRASIL. Ministério da saúde. Portaria no 399, de 22 de fevereiro de 2006. Brasília, DF, 2006a. Disponível em: http://dtr2001.saude.gov.br/sas/PORTARIAS/Port2006/GM/

GM-399.htm. Acesso em: 9 março de 2016.

[32] MINAYO, M.C.DE S.; DESLANDES, S.F. Análise da implantação da rede de atenção às vítimas de acidentes e ص violências segundo diretrizes da Política Nacional de Redução da Morbimortalidade sobre Violência e Saúde. Ciência, saúde E Coletiva, v.14, n.5, p.1641-1649, 2009.

[33] BITTENCOURT, R.J.; HORTALE, V.A. A qualidade nos serviços de emergência de hospitais públicos e algumas considerações sobre a conjuntura recente no município do Rio de Janeiro. Ciência e Saúde Coletiva, Rio de Janeiro, n.12, p.1413-8123, 2007.

[34] GOMES, A.P. et al. A formação médica: revisitando Paulo Freire. Revista Digital de Educação Permanente em Saúde, v.1, p.236, 2004.

[35] HARTZ, Z.M.A. Princípios e padrões em meta-avaliação: diretrizes para os programas de saúde. Ciência e saúde coletiva. Rio de Janeiro, v.11, n.3, p.733-738, 2006.

[36] SAÙDE, Rede hospitalar de urgência/emergência. Lisboa: Direcção-Geral da Saúde, 2001 